\title{
EN TORNO A UNA FILOSOFÍA POLÍTICA SOBRE LA NOCIÓN DE INDIO EN LA CRÓNICA MEXICANA DE HERNANDO ALVARADO TEZOZÓMOC ${ }^{1}$
}

\author{
Towards a Political Philosophy about the Notion of Indian in Hernando Alvarado \\ Tezozómoc's Crónica Mexicana
}

Alejandro Viveros Espinosa*

\begin{abstract}
RESUMEN
Este escrito busca posicionar algunas reflexiones filosófico-políticas en torno a la noción de indio en México colonial presentes en la Crónica Mexicana (1598) de Hernando Alvarado Tezozómoc. Para ello desarrollaremos tres dimensiones de análisis e interpretación. El primero atiende a un problema conceptual a través de una revisión y selección de algunas propuestas relativas a la noción de indio en términos críticos y propositivos. El segundo refiere al indio y su escritura como una narración histórico-literaria que canaliza un proceso de reconstrucción identitaria. Finalmente, el tercero señala un ejercicio interpretativo sobre la Crónica Mexicana que busca reconocer las reflexiones filosófico-políticas de Alvarado Tezozómoc, destacando sus propuestas respecto de un proyecto civilizatorio moderno bifurcado en el Nuevo Mundo.

Palabras clave: filosofía política, indio, escritura, Crónica Mexicana, Hernando Alvarado Tezozómoc.

\footnotetext{
${ }^{1}$ Resultado del Proyecto Fondecyt de Iniciación No 11160012, titulado: “Convivencia interétnica y traducción cultural. Aproximaciones sobre el contenido filosófico-político de las crónicas de indios en el mundo cultural novohispano (1576-1650)".

* Facultad de Filosofía y Humanidades, Centro de Estudios Culturales Latinoamericanos, Universidad de Chile. Santiago, Chile. Correo electrónico: aviveros@u.uchile.cl

Artículo recibido el 3 de marzo de 2016. Aceptado el 18 de enero de 2017.
} 


\begin{abstract}
This essay posits certain political and philosophical reflections towards the notion of Indian in colonial Mexico through Hernando Alvarado Tezozomoc's Crónica Mexicana (1598). To this purpose we will deploy three hermeneutic dimensions. The first builds a theoretical and methodological questioning related to the notion of Indian in a critical and proposal level. The second refers to the Indian and his literacy in terms of a historical and literary narrative, which address a process of identity reconstruction. Finally, the third points out an interpretative exercise on the Crónica Mexicana in order to reveal Alvarado Tezozómoc's political-philosophical reflections, remarking his proposals of a bifurcated modern civilizational project in the New World.
\end{abstract}

Keywords: Political Philosophy, Indian, Literacy, Crónica Mexicana, Hernando Alvarado Tezozómoc.

\begin{abstract}
¿Cuáles son los lugares, emplazamientos y desenlaces discursivos a los que debemos acudir para encontrar esa filosofía dispersa -ya que no podemos hacerlo en la tradición de nuestras universidades ni en nuestras escuelas de filosofía? No se trata, por supuesto, de buscar filosofía en todos y cada uno de los registros habituales de la literatura, la historiografía, el pensamiento jurídico-político, la antropología o materias afines, sino de encontrar y examinar crítica y reflexivamente fragmentos de discurso (o sistemas de dispersión) cuyos registros, justamente por su indudable perfil y hondura filosófica, se reconocen incidental y transitoriamente entretejidos en textos literarios, historiográficos, jurídicos-políticos, antropológicos y aun técnico-científicos particulares (Ortega Esquivel, 2011).
\end{abstract}

Este escrito tiene por objetivo distinguir y proponer algunos elementos útiles para una comprensión e interpretación filosófico-política ${ }^{2}$ referida al

\footnotetext{
${ }^{2}$ Podemos sostener que la filosofía política responde -en términos generales- a un cuestionamiento por la vida en comunidad, por las formas de gobierno, la justicia, los derechos y la libertad. La filosofía política es parte de un cuestionamiento por el ser humano en la pólis, es decir, por el mundo del "animal político" (Aristóteles, 1988: 50-51) y, ciertamente, por su capacidad de articular diferentes modos de vida y convivencia, constituyentes de diversas costumbres, culturas e identidades. La referencia a Aristóteles no es casual. Su influencia en la trayectoria de la filosofía política en América colonial es fundamental. Recogemos las problematizaciones realizadas por Zavala (1994), en su análisis sobre la "evangelización" como el trasfondo de la filosofía política en América colonial, principalmente a través del concepto de "servidumbre natural". Asimismo, relevamos las propuestas de Pagden (1988) respecto de la dicotomía civilizado/bárbaro como parte de un "problema de reconocimiento" y "legitimación" del proyecto colonial hispano-occidental. Consecuentemente, es posible delinear una relación directa entre la teoría política de Aristóteles y el contexto colonial americano. Afirmamos que esta relación impacta también en las producciones históricas y literarias, dentro de las cuales destacamos el caso de Hernando Alvarado Tezozómoc.
} 
pensamiento de Hernando Alvarado Tezozómoc (1524?-1609?), particularmente en su problematización respecto de la noción ${ }^{3}$ de indio, presente en su célebre Crónica Mexicana (1598). Con este objetivo dirigiremos nuestro análisis en tres momentos interrelacionados. El primero retoma ciertos conceptos y propuestas en las que reconocemos algunos elementos teóricos útiles -en un sentido abiertorelacionados con nuestro problema en torno a la noción de indio. El segundo se dirige a problematizar la escritura de los indios como una producción históricoliteraria, atendiendo a este asunto como un espacio de enunciación de sujetos de escritura. Ambos momentos nos permiten relocalizar la profundidad y la dificultad de definir la noción de indio. Consecuentemente, el tercer momento pretende operativizar los conceptos tratados, esto significa, funcionalizar una interpretación compleja que se desarrolla en una ejemplificación, en ningún modo casual, a través de la Crónica Mexicana de Tezozómoc. Encontraremos en este texto, siguiendo un cuestionamiento filosófico-político, algunas claves útiles para la interpretación sobre la noción de indio en México colonial.

\section{EN TORNO A LA NOCIÓN DE INDIO}

Buscamos establecer algunas claves útiles para nuestro problema relativo a la noción de indio en México colonial. Para ello, destacamos la reflexión de Edmundo O'Gorman en su célebre ensayo titulado La invención de América donde no solo presenta un horizonte de pregunta ${ }^{4}$ en concordancia con el propósito

\footnotetext{
${ }^{3}$ El término "noción" tiene como raíz el vocablo latino notio, el cual es una traducción de las palabras griegas énnoai (idea "en general") y prólepsis (idea o imagen "anticipada"). El término "noción" es atribuido a Cicerón, quien la usa como sinónimo de "pensamiento", "idea", "imagen en el espíritu" o "designio" (Ferrater Mora, 1994: 290). Entendemos al término "noción" destacando que: "En el sentido de 'pensamiento', 'idea', “concepto', 'representación' y otros vocablos análogos, el término noción ha sido, y sigue siendo empleado de modo muy general; se llama noción a la idea o concepto de algo, y más específicamente a una idea o concepto suficientemente básico" [...] "En la actualidad el vocablo 'noción' es usado en español sin un significado muy preciso, como equivalente a 'representación' (mental), 'concepto', 'idea', etc. También es usado como equivalente a 'noticia'. De emplearse como vocablo 'técnico', convendría precisar en cada caso su significado". (Id. 290). Destacamos también el término "nociones comunes" o notiones communes, atribuido a "Crisipo y otros estoicos", con el cual "daban a entender una serie de ideas y nociones básicas que la mente reconoce como adecuadas y fundamentales para cualquier ulterior desarrollo del conocimiento" (Id. 291). Entonces, nuestra pregunta por las "nociones" busca establecer un conjunto de elementos teóricos, accesibles y comprendidos por todos, que han sido construidos a lo largo de un complejo desenvolvimiento historico-cultural, y que determinan, en este caso, el conocimiento relativo a un término específico: el indio.

${ }^{4}$ Por horizonte queremos retomar, principalmente la comprensión hecha por la fenomenología. La noción de horizonte, siguiendo a Husserl, nos permite incorporar un enlace entre la expectativa y la
} 
de nuestro escrito, sino que nos permite profundizar en el "sentido histórico" que rodea el problema del indio y su construcción como parte del proceso de "invención" de lo americano. Siguiendo a O'Gorman, es fundamental considerar una problematización en términos de la construcción de la "idea” de América. Esto invita a pensar nuevamente en el kairós del 12 de octubre de 1492 bajo el significado de un "encuentro-choque". Bajo la idea de un encuentro-choque donde es posible advertir la oposición entre lo europeo y lo otro, que constituye durante el siglo XVI una matriz de comprensión referida a un proceso de homogeneización sobre la alteridad (otro). Esto es bien tratado por O'Gorman quien con su tesis central determina que el estatus del descubrimiento depende, en gran medida, de quien interpreta, poniendo así el acento en la posición de enunciación. En este sentido, es preciso re(de)-construir la historia, no solo del descubrimiento de América, sino de la idea de América y de su necesario proceso de legitimación en términos históricoculturales y filosófico-políticos. Esta trayectoria, podemos establecer, es coperteneciente y atingente a la idea o noción de indio y sus concomitantes procesos de reconstrucción acontecidos no solo en el contexto novohispano, sino en todo el Nuevo Mundo. En consecuencia, lo determinante siguiendo esta propuesta es reconstruir la historia de la idea del indio en tanto que un "ejercicio de invención".

Respecto del problema del indio como "ejercicio de invención" recogemos el análisis de Guillermo Bonfil Batalla en su artículo El concepto de indio en América donde describe varias de las interpretaciones hechas sobre el indio durante buena parte del siglo XX. En este artículo se detallan perspectivas que, por una parte, involucran definiciones académicas en torno a una discusión antropológica e historiográfica y, por otra, cuestionan el alcance político del problema del indio encausado en el "indigenismo" y la "política indigenista". Para Bonfil Batalla, "lo indio" se ha construido como una clasificación identitaria conforme a cuatro criterios generales: "el biológico, el lingüístico, el cultural y el psicológico" (106108). Entonces, la invención del indio como categoría de clasificación identitaria implica una ruptura y un reinicio respecto del pasado precolombino. El indio

experiencia, puesto que "toda experiencia tiene un horizonte experiencial" en tanto una "estructura" que está referida al mundo de la vida como un "margen o estructura co-presente", constituyendo un "mundo de asuntos, de co-datos" (Husserl: 26-38). Para Heidegger la temporalidad funciona como horizonte de cualquier comprensión del ser, donde horizonte equivale a los límites en el marco de la pregunta tanto por el sentido y la existencia (Heidegger: 25-29), como por la temporalidad (historicidad) y la trascendencia del mundo, comprendiendo al concepto de horizonte como unidad extática de la temporalidad (Heidegger, 2003: 379-396). En este sentido, la noción de horizonte se nos presenta como el límite de la totalidad de las cosas dadas y, a la vez, como lo que las constituye en cuanto tales (Kuhn, 1940: 106-123). Incorporamos a ello una lectura respecto del horizonte de pregunta en tanto que un cuestionamiento relativo a la vivencia como sabiduría de vida (Ette, Viellogische Philologie, 2013: 58-59). 
forma parte de un ejercicio de "invención e imposición colonial" a través del cual, y conjuntamente, "nace la cultura indígena" (115). La conclusión de su estudio recalca que el indio es una "categoría colonial" con alcance social e identitario supraétnico y plural que se genera a partir de un proceso de homogeneización que enmascara la especificidad histórica de todo grupo humano (etnia) clasificado como indio.

En un sentido crítico y polémico, es posible integrar a nuestro análisis el trabajo de Guy Rozat en su texto Indios imaginarios e indios reales en los relatos de la conquista de México donde desmonta de forma directa los imaginarios que se han configurado en relación al indio en México desde su construcción colonial. La perspectiva desarrollada por Rozat responde a una revisión crítica de los materiales a través de los cuales se ha construido la noción de indio, es decir, las "fuentes coloniales" y los "textos indígenas de la conquista". Esto le permite concluir que se han constituido dos dimensiones del indio, una imaginaria y otra real. La primera, es decir, la "imaginaria" responde a una construcción realizada sobre el indio en términos homogeneizantes y esencialistas. El análisis de Rozat es detallado, precisamente respecto de los modos en los cuales se ha cooptado o derechamente tergiversado la idea de indio encubriendo a la segunda dimensión, esto es, al "indio real". El "indio real" es aquél que estando presente se vuelve ausente, y que se utiliza como fundamento identitario en el ideario nacional mexicano. En suma, el problema del contenido del "indio imaginario" en contraste con el "indio real" atrae nuestra atención, principalmente debido a su continuidad durante el siglo XXI. Esto impacta el problema sobre la noción de indio desde su condición y definición colonial, pues reconfigura su sentido conforme a idearios encubiertos pero funcionales (o bien funcionalizados) en torno a un indio que no responde a su realidad objetiva y material, sino a una construcción "cristiano-occidental" reutilizada por el imaginario nacionalista, en este caso, mexicano.

Ahora bien, siguiendo una interpretación que tensiona el horizonte de pregunta de sobre la noción de indio, queremos incorporar algunas reflexiones en torno a los conceptos de "mestizaje cultural" y "códigofagia". De este modo los define Bolívar Echeverría en Las ilusiones de la modernidad:

El mestizaje cultural ha consistido en una "códigofagia" practicada por el código cultural de los dominadores sobre los restos del código cultural de los dominados. Ha sido un proceso en que el devorador ha debido muchas veces transformarse radicalmente para absorber de manera adecuada la substancia devorada; en el que la identidad de los vencedores ha tenido que jugarse su propia existencia intentando apropiarse de la de los vencidos (63). 
Echeverría posiciona claramente ambas nociones como un "devorar" constante entre "códigos culturales". Es ahí donde de forma "codigofágica" se construye un tipo de subjetividad culturalmente mestiza, fronteriza, en movimiento. Hablamos de una subjetividad que no encaja con el indio "en su sentido estricto", sino que apropia, agencia y re-direcciona "en sentido amplio" los horizontes de comprensión e interpretación relativos a la conceptualización llamada: el indio. Esto implica plantear nuevamente la pregunta por la identidad cultural. Frente a ello indica Bolívar Echeverría en La modernidad de lo barroco:

Si la identidad cultural deja de ser concebida como una sustancia y es vista más bien como un "estado de código" -como una peculiar configuración transitoria de la subcodificación que vuelve usable, "hablable", dicho código-, entonces, esa "identidad" puede mostrarse también como una realidad evanescente, como una entidad histórica que, al mismo tiempo que determina los comportamientos de los sujetos que la usan o "hablan", está siendo hecha, transformada, modificada por ellos (31).

En consecuencia, la construcción de la noción de indio como "estado de código" compone una subjetividad "evanescente". El indio como identidad cultural (código cultural) se forja en sus posibilidades para devorar y ser devorado. El abandono de una perspectiva sustancialista (en favor de una lectura semiótica) aleja a Echeverría del esencialismo culturalista latinoamericano. Luego, la "realidad evanescente" es parte de la transformación bajo la cual lo indio está siendo constantemente re-construido en la medida en que lo "usan y hablan". Pero, ¿quiénes usan y hablan esos códigos? ¿Quiénes los transforman y reconstruyen? Sobre este cuestionamiento, indica Bolívar Echeverría en Modernidady blanquitud:

Pero lo más importante y sorprendente de todo esto es que fueron los mismos indios quienes asumieron la agencia o sujetidad de este proceso, su ejecución; hecho que llevó a que éste se realizara de una manera tal que lo que esa reconstrucción iba reconstruyendo resultaba ser algo completamente diferente del modelo que pretendía reconstruir. De ella resultaba una civilización occidental europea retrabajada en el núcleo mismo de su código precisamente por los restos sobrevivientes de ese código civilizatorio indígena que esa civilización tenía que asimilar para poder revivirla. Jugando a ser europeos, no copiando las cosas o los usos europeos, sino imitando el ser europeo, simulando ser ellos mismos europeos, es decir, repitiendo o 'poniendo en escena' lo europeo, los indios asimilados montaron una muy peculiar representación de lo europeo. En una representación o imitación que en un momento dado, asombrosamente, había dejado de ser tal y pasado a ser una realidad o un original: en el momento mismo en que, ya transformados, los indios se percataron de que se trataba de una representación 
que ellos ya no podían suspender o detener y de la que, por lo tanto, ellos mismos ya no podían salir; era una 'puesta en escena absoluta', que había transformado el teatro en donde tenía lugar, permutando la realidad de la platea con la del escenario (191).

Seguimos a Echeverría, particularmente en su noción sobre los restos sobrevivientes de los códigos culturales indios y su reconstrucción a través de los códigos culturales europeos (hispanos) impuestos durante la colonización. La clave que entrega Echeverría está en aquel "poner en escena” llevado a cabo por los indios, en el cual se fraguó su supervivencia cultural e identitaria. Finalmente, aquella "representación o imitación" de un mundo desconocido en una "imitación" creadora, reconfigurada por sus propios y reinventados horizontes de comprensión, alterada en virtud de las circunstancias y los contextos, que se construye permutando "la realidad de la platea con la del escenario".

\section{ALGUNAS IDEAS SOBRE EL INDIO Y SU ESCRITURA}

Pues bien, dentro de aquellos indios que se vieron obligados a "ponerse en escena” y desplegar los códigos culturales europeos, remarcamos un grupo especial, a saber, los indios que escriben. Nos referimos a aquellos que aprendieron y usaron el código alfabético como vehículo para sobrevivir, negociar y reconducir su experiencia histórica. Aquellos indios que escribieron, que aprendieron y usaron el código cultural alfabético, han sido catalogados de diferentes maneras, como humanistas y letrados (Garibay, 1954; León-Portilla, 1964; Romero, 2003, 2011), como ladinos (Adorno, 1992; Bernand 2001; Cornejo Polar, 2011), como zonas de contacto (Pratt, 1991), como passeurs (Gruzinski, 2005) o bien como traductores culturales (Añón, 2012; Payàs, 2011).

Asimismo, deseamos incorporar un concepto complementario. Hablamos del concepto de "crónica mestiza" acuñado por Martin Lienhard, especialmente porque nos abre a la inclusión de elementos directamente relacionados con una dimensión histórico-literaria en las producciones discursivas realizadas por los indios durante la primera etapa de la colonización americana. Así define Lienhard este concepto en La crónica mestiza en México y el Perú hasta 1620:

Atribuimos el carácter "mestizo" a aquellas crónicas que, casi independientemente del origen étnico de sus autores (indígenas, mestizos, españoles), reelaboran materiales discursivos o reales de la historia americana a través de unos procedimientos narrativos (verbales y/o pictográficos) de tradición heterogénea: indígena y europea (105). 
A través de las "crónicas mestizas" funcionalizadas como pivote conceptual es posible elaborar un ejercicio teórico-crítico relativo a un discurso identitario en construcción que contiene elementos histórico-literarios dispuestos a ser pensados y utilizados de forma no dogmática y abierta a nuevos horizontes de pregunta que configuran "las premisas de una nueva conciencia global, histórica, política y cultural" (Lienhard, 1983:107).

Sin embargo, nuestra perspectiva nos lleva a pensar junto con Echeverría y su método "codigofágico" puesto en movimiento, precisamente, en subjetividades alternativas que catalizan y redireccionan discursos y problemas de profundo carácter identitario a través de la escritura. Queremos continuar la lectura de Echeverría en una propuesta que nombramos como "escritura codigofágica". Hablamos de una escritura que permea y trasvasija los códigos, que es alfabética pero que contiene ecos no-alfabéticos. Una escritura que intenta posicionarse entre modos europeos de explicación, de fundamentación y argumentación, de articulación discursiva muchas veces relativa a la tradición bíblica, clásica o humanista, en conjunto con aquellas "fuentes otras", principalmente referidas a tradiciones orales, a soportes no-alfabéticos y a experiencias polisensuales o multisensoriales.

En esta escritura codigofágica se cruzan y yuxtaponen varios horizontes de comprensión y preguntas útiles en nuestro cuestionamiento, a saber, el filosófico, el histórico, el literario, el semiótico y, por cierto, el político. Esto acontece porque es una escritura que precisa explicarse, que tiene mucho por decir, que se dirige al otro, al europeo, para "hacer notar" que la historia del indio (es decir, su construcción) puede ser escrita también por ellos. A través de esta escritura codigofágica buscamos reconocer cómo los llamados "indios", escribiendo y traduciendo, llevan a cabo aquella "puesta en escena" en la cual el "devorarse unos a los otros" conduce una construcción histórico-literaria donde encontramos elementos significativos para cualquier cuestionamiento o aproximación filosófico-política sobre la noción de indio.

Estas "escrituras codigofágicas", estas "crónicas mestizas", son múltiples y acarrean una acuciosa revisión de sus contenidos. El recurso narrativo de estas obras responde a diferentes géneros y clasificaciones histórico-literarias (crónicas, historias, relaciones, cartas, entre otras); destacamos su extraordinara relación intertextual con materiales y soportes no-alfabéticos que evidencian la versatilidad y la movilidad entre códigos culturales disímiles en fricción, adaptación y apropiación. Ahí se compone una dimensión histórico-literaria que avanza hacia la rearticulación de reflexiones filosófico-políticas presentes en los textos y que, a su vez, colaboran en la construcción de la noción de indio. Finalmente, estos derroteros nos conducen a una búsqueda relacionada con el indio como noción abierta, en constante invención y transformación. La atención a estas producciones histórico-literarias de los “cronistas mestizos novohispanos” está en directa relación 
a cómo estas subjetividades se construyen al momento de pensar su lugar en los albores de la "modernidad occidental" (Echeverría, 2005: 19-28).

En suma, la vectorización de sentido en la noción de indio en México colonial responde a un proceso de imposición civilizatoria a escala local/global llevado a cabo a través del orden colonial hispano y en el cual el indio también se encarga de participar en su construcción discursiva. En este contexto, el énfasis en nuestro acercamiento está centrado en las posibilidades de interpretación que se presentan en las producciones histórico-literarias hechas por estos "sujetos de escritura indios" o bien "cronistas mestizos". Sostenemos que en estas producciones se plasman ideas, perspectivas y argumentos útiles en la problematización filosóficopolítica sobre la noción de indio como una identidad cultural en reconstrucción.

\section{EL CASO DE HERNANDO ALVARADO TEZOZÓMOC}

Varios debieron ser los textos escritos por Hernando Alvarado Tezozómoc (1524?-1609?), entre documentos, papeles varios y, ciertamente, pensamientos y narraciones; dos de estos han llegado hasta nuestros días. En castellano la Crónica Mexicana (1598) y en náhuatl Crónica Mexicáyotl (1609)5. Nos abocaremos a la primera de estas dos obras. La Crónica Mexicana es una obra redactada en castellano con manos e interpretación indias. No es precisa una indicación sobre la fecha de elaboración, tampoco sobre su término, más bien podemos adscribir la hipótesis de que es una obra "en movimiento" (Ette, 2008) probablemente escrita

\footnotetext{
${ }^{5}$ La Crónica Mexicáyotl (1609) puede ser considerada como una autotraducción y/o traducción cultural en directa relación con la versión castellana. En este sentido, es preciso posicionar una interpretación co-relacional para ambos textos a partir de la cual sus entretejidos narrativosliterarios conducen una reconstrucción de la historicidad mexica-tenochca fragmentada en dos lenguas y dos receptores diferentes. No obstante, respecto de las partes del texto podemos reconocer: la introducción general, la salida de los mexicas desde Aztlan, la migración y la fundación de Tenochtitlán, y las genealogías de la élite (tlatoque tenochcas). Ya la introducción muestra un cuidadoso Tezozómoc entregando los comentarios que darán sentido al texto, la historia mexicatenochca, que debe afrontar las historias de otras élites (por ejemplo, la de Tlatelolco o Texcoco), destacando el énfasis en su condición social y linaje. Podemos decir que son las historias familiares, los linajes de la élite mexica, el centro del relato en la versión náhuatl. Sin embargo, la descripción de las genealogías de los señoríos mexicas, siendo exhaustivas en la versión náhuatl, no lo son en la versión castellana, que refiere y recoge los acontecimientos militares con detalle. Tezozómoc en su Crónica Mexicáyotl re-genera una historia basada en la tradición oral y en los códices, dotando de justo reconocimiento e importancia a particulares elementos políticos y culturales dentro de la sociedad mexica-tenochca precortesana. Finalmente, Tezozómoc le habla a las nuevas generaciones de la élite mexica-tenochca, le habla con todo el peso de la historia en forma didáctica (magistra vitae). En su Crónica Mexicáyotl los venideros han de poder encontrar el sentido de su historicidad en el orden colonial y, ciertamente, de su memoria social y cultural (Romero, 2007).
} 
y pensada con paciencia y cuidado a lo largo de varios años. Hay una opinión consensuada en fechar la elaboración de la Crónica Mexicana alrededor de 1598, año del cual proviene su copia más antigua ${ }^{6}$. Para esta fecha, según la datación de su vida, seguramente Tezozómoc ya tenía una edad madura.

El escrito rescata dimensiones que otros textos culturales realizados por indios no alcanzan. Sirve para comprender el grado de apropiación e interconectividad entre dos mundos, y cómo este indio de élite, este cronista mestizo, persiste en la re-significación de su historicidad. Su estilo intercala, mezcla, palabras y frases que colorean el relato, así también se deja ver un espíritu subyacente, una "prístina sencillez", que conserva la oralidad, la tradición oral, que trasluce en su prosa algunas veces fuerte, otras suave. Señala Ángel María Garibay en Historia de la literatura náhuatl: "La lengua castellana en Tezozómoc es balbuciente a veces, incorrecta otras, siempre ágil y colorida" (302) en la cual es posible reconocer la recepción de la literatura clásica y humanista, y la labor escritural en las "crónicas, relaciones y cuestionarios" en las que probablemente él mismo hubo de colaborar directamente debido a su condición de oficial administrativo y traductor o nahuatlato (Payàs, 2011; Romero, 2003). Sobre este asunto, es interesante relevar la relación y la circulación de las "fuentes otras" (anales, títulos primordiales, lienzos, mapas, cantos, entre otras) desde las cuales Tezozómoc trabajó su texto cultural (Gruzinski, 2004; Lockhart, 2013; Navarrete, 2015). No obstante, el gesto de Tezozómoc de re-elaborar la historia mexica en forma de crónica es ciertamente una evidencia de su interrelación con los modelos europeos, probablemente, como parte de su acervo cultural necesario para su proyecto histórico-literario.

En cuanto a la composición narrativa de la obra, es importante indicar que Tezozómoc rescata (o bien rememora) las causas de las guerras precortesianas y el resultado de estas, destacando las conductas de los monarcas mexicas-tenochcas en forma de diálogos, con un estilo fuerte, a veces descuidado, explicitando la vida diaria de la élite india, sus historias, los modos de conservación de la tradición y el trato de los gobernantes (tlatoani). La Crónica Mexicana contiene ciento doce capítulos que se desarrollan cronológicamente y donde la continuidad no se interrumpe excepto por los cortes que marca el capitulado que son utilizados como paratextos e introducen el relato. No obstante, es posible distinguir tres partes temáticas en la Crónica Mexicana. La primera parte está referida a la partida de los mexicas de Aztlan Chicomoztoc, su migración y la llegada al valle de Anáhuac, al islote donde se funda Tenochtitlán. Aquí el relato, se condensa en los primeros capítulos

\footnotetext{
${ }^{6}$ Nos referimos al manuscrito No 117 de la Hans P. Kraus Collection. El manuscrito se encuentra en la Biblioteca del Congreso de Estados Unidos de América. A pesar de estar incompleto, es hasta el momento el manuscrito más antiguo que se conoce, y probablemente el "original" (Alvarado Tezozómoc, Crónica Mexicana, 2010: 7-27).
} 
de la obra y tiene como característica la reiterada mención a las promesas que Huitzilopochtli hace a los mexicas, sobre un lugar donde podrán erigir su ciudad y su reino. Una vez que esto ha acontecido, una vez cumplida la promesa divina, se cierra la primera parte (Alvarado Tezozómoc, Crónica Mexicana, 2010: 53-64). La segunda parte se inicia en el capítulo sexto y concluye en el noveno, refiere a los primeros ańos de los mexicas en Tenochtitlán, desde la muerte de Acamapichtli, el primer tlatoani, hasta la coronación de Itzcóatl y la guerra con Azcapotzalco. Aquí el relato es atravesado por la condición de opresión y subalternidad que mantuvieron por parte de los tecpanecas (Id. 64-76). La tercera parte, más extensa que las dos anteriores, contiene la historia de las guerras y conquistas de los mexicas luego de su liberación de Azcapotzalco. Esta parte de la Crónica Mexicana se inicia en la mitad del capítulo noveno y prosigue hasta el final de la obra, donde Tezozómoc concluye su relato con la llegada de Cortés y sus tropas a Tlaxcala (Id. 76-484).

Pues bien, y respecto a la construcción narrativa y las posibilidades de interpretación, señala José Rubén Romero Galván en Los privilegios perdidos. Hernando Alvarado Tezozómoc, su tiempo, su nobleza y su Crónica Mexicana:

La historia allí relatada concierne primordialmente a un grupo social: los pipiltin, la nobleza mexicana. Las acciones guerreras que este grupo llevó a cabo, sus triunfos, sus derrotas, sus preocupaciones, la sucesión de sus miembros en los cargos importantes del gobierno, la milicia y el clero, son los hechos que retienen la atención del autor. En las escenas de esta historia, el fondo escénico es la extraordinaria ciudad de México Tenochtitlán, el pueblo interviene sólo como los coros en las obras de teatro clásico, y las figuras protagónicas que se mueven continuamente y ocupan siempre los primeros planos son el huey tlahtoani, el cihuacóatl, los pipiltin... Es por lo tanto la historia de la clase que ocupó la cúspide de la pirámide social mexica, aunque, ciertamente, en el relato se dibuje también, casi velada, la otra historia, aquella de quienes se encontraban en la base de la estructura de la sociedad indígena prehispánica (119).

Romero Galván reconoce la trayectoria central de la obra de Tezozómoc. En su narración hay una recreación de un grupo humano (una élite) que supo organizarse y dominar a otros desde "un fondo escénico" llamado MéxicoTenochtitlán. Reconoce asertivamente Romero Galván que esta versión de la historia obscurece otras, a saber las de aquellos dominados por los mexicastenochcas.

Como hemos señalado, nuestro objetivo es resaltar -desde el texto de Tezozómoc- algunos elementos filosófico-políticos sobre la noción de indio en México colonial. En este sentido, no podemos dejar de lado ciertas claves de lectura que canalizan y explican el modo de vida y gobierno de los "indios" mexicas. Esto nos lleva a preguntar: ¿quiénes son los “indios” mexicas-tenochcas en la Crónica 
mexicana? A través del texto Tezozómoc remarca la relación y fuerte identificación entre los mexicas-tenochcas y su dios guía Huitzilopochtli, presentado como dios protector, como dios principal. Ya al salir de Aztlan y, ciertamente, desde la fundación de México-Tenochtitlán, es siempre a Huitzilopochtli a quien los mexicas-tenochcas dedican su religión. Verbigracia, sostiene Hernando Alvarado Tezozómoc al inicio de su Crónica Mexicana: "Tenían <en> las lagunas de su tierra, Aztlan, un cu y en ella el templo de Huitzilopochtli, ydolo dios de ellos" (53). La relación mesoamericana entre la política y la religión es clave en cuanto que canaliza una profundo sentido histórico y existencial (López-Austin, 2014: 161-185). La crónica de Tezozómoc confirma este análisis. En este contexto, podemos indicar que hay un acercamiento dicotómico en torno a los dioses precortesianos y, por cierto, una explicación que debe encontrar el sentido de los rituales y ceremonias en honor de Huitzilopochtli, especialmente a los sacrificios humanos, proscritos con la llegada del orden colonial. Con ello, es menester también destacar cómo Tezozómoc relata la capacidad bélica y la valentía de los mexicas-tenochcas, su orden y cohesión social, política y militar. Por ejemplo, luego de su liberación de Azcapotzalco y en la voz del rey Itzcóatl, indica Hernando Alvarado Tezozómoc en su Crónica Mexicana:

Comiença el memorial de los balerosos soldados conquistadores de Azcapuçalco: el primero, Cuahtleoatl segundo, Tlaacahuepan y luego Tlaatolçaca.

luego otro, Epcoatl y luego Tzompantzin

Los hijos que fueron del rrey Huitzilyhuitl, capitanes soldados de estos: el primero, llamado Tlacaeleltzin

y el segundo Huehueçacan

y Huehue Moteç̧uma

y Çitlalcoatl,

Aztecoatl

y el otro, Axicyotzin

y Cuauhtzimitzin

y el otro, Xiconoc

De manera que son éstos los prençepales balerosos mexicanos y los fundadores de Mexico Tenuchtitla $<\mathrm{n}>\mathrm{y}$ los primeros capitanes y conquistadores que ganaron $\mathrm{y}$ ensancharo $<\mathrm{n}>$ esta gran rrepública y corte mexicana, y las tierras y pueblos que pusieron en suxeçión y cabeça de Mexico Tenuchtitlan; que estos tales prençipales por ellos a sido y es cabeça de Mexico Tenuchtitlan y su grandeza y señorío que oy es, siendo primero Mexico Tenuchtitlan (80). 
En la cita Tezozómoc hace un reconocimiento detallado a los guerreros de la liberación, a los capitanes y soldados mexicas-tenochcas, y a su élite ("prençepales) que logra hacer de "esta gran república y corte mexicana" el centro político ("cabeça") del mundo precortesiano. Tezozómoc despliega una apreciación caballeresca que enaltece las virtudes guerreras y políticas de una élite, siendo esto evidente en la descripción de este tipo de personajes desarrollada a lo largo del texto. En suma, se nos presenta la historia política de una etnia particular (calpulli) guiada por su dios Huitzilopochtli que, como seńala Hernando Alvarado Tezozómoc en su Crónica Mexicana:

Pues aún no abía Çihuacoatl ni rreyes pasados, sino solo bosotros, mediante el gran fauor, ayuda, socorro del tetzahuitl Huitzilopochtli, <que> aun por su mandado dixo luego lo acometiésemos, que él yba con bosotros. Pues esto es ansí mexicanos, agora < que > sois flor del mundo, no a de acouardar $\mathrm{u}<\mathrm{uest}>$ ro alto, valeroso ánimo, que todo es un solo día de trauajo y es ganar onrra y fama para siempre jamás y bernán en rreconosçimiento de más obidientes $n<$ uest>tros henemigos y basallos lexanos, pues $\mathrm{n}<$ uest $>$ ra propia patria y nación hazemos, contra ellos, justicia por guerra y derramamiento de sangre $\mathrm{n}<$ uest $>$ ra $(198)$.

Ecce, la historia del "socorro de Huitzilopochtli", de su éxito militar, de su “propia patria y nación”, de su modo de gobierno y policía (“justicia por guerra y derramamiento de sangre"), que domina y vuelve a Tecnochtitlán una "flor del mundo". Queremos seguir la metáfora de "flor de mundo" porque refiere al lugar donde acontece un proyecto civilizatorio precortesano, podemos sugerir, divergente o diferente pero en inexorable colisión con el proyecto civilizatorio moderno-occidental. En este contexto, es prudente relevar un sentido políticoreligioso como trasfondo del proyecto civilizatorio mexica-tenochca. Sobre este asunto insiste Hernando Alvarado Tezozómoc en su Crónica Mexicana:

Dixo Ahuitzotl que tubiesen especial cuidado de guardar sus tierras, haziendas, y cuidado al seruiçio y tributo de tetzahuitl Huitzilopochtli, y que mediante abía de $<$ en>trar en aquellas tierras y suxetallas a serbidumbre, como es de su propio ofiçio y cargo el suxeto de estrangeros, que a eso bino de lexos tierras, a estar en medio de todo este mundo, yrlo ganando y descubriendo para <que> le rreconozcan todas las nasçiones del mundo y sujetos a él, $<\mathrm{y}>$ a esto se crían, nasçem los de la nación mexicana para el ganar y atraer a ellos y a $\mathrm{n}<\mathrm{uest}>$ ro dios Huitzilopochtli basallaxe (347-348).

La cita nos dirige hacia un reconocimiento y una reivindicación de un modelo de carácter político-religioso basado en su proyección civilizatoria, que adscribe una dimensión móvil y adaptativa en la noción de indio mexica-tenochca como 
un "civilizador" instrumentalizado por Huitzilopochtli, esto es, por su religiosidad. Esta noción de indio como conquistador y civilizador es construida e integrada en el horizonte de comprensión europeo, esta vez, bajo la letra de uno de ellos. Tezozómoc, como muchos otros en su tiempo, es capaz de re-establecer una historicidad específica que contiene un proyecto civilizatorio tensionado por la modernidad occidental. Tezozómoc desarrolla un especial "ethos histórico" (Echeverría, 2005) que perturba la linealidad y la uni-direccionalidad de la reinscripción histórico-literaria porque interviene desde dentro en la lucha por la identidad cultural. Como traductor cultural se dedica a registrar los diferentes modos de la vida política y social mexica-tenochca (tradiciones, costumbres, genealogías), donde despliega motivaciones representativas de su grupo socio-cultural entendido, esta vez, a través de la noción de indio en tanto que mexica-tenochca, en tanto que conquistador y civilizador. En rigor, ese es el indio mexica-tenochca para Tezozómoc, puesto que su relato también construye a un “indio imaginario" (Rozat, 1993) explicando e inventando su propia historicidad, su proyecto civilizatorio constitutivo de una modernidad bifurcada (Echeverría, 2001).

Deseamos profundizar en este cuestionamiento en torno a la contraposición de proyectos civilizatorios, es decir, en la tensión entre Occidente (su creación expansión-) y lo "otro", es decir, los "otros mundos" en los cuales subjetividades tales como Tezozómoc deben redefinir su lugar. Este encuentro-choque establece un cuestionamiento sobre los horizontes simbólicos y los imaginarios que Occidente construye conforme a su propia trayectoria civilizatoria. El proyecto civilizatorio de la modernidad occidental condena y purga todo proyecto alternativo, lo devora en su propio horizonte, mas no por ello lo clausura (Bolívar Echeverría, 2005, 2010). Siguiendo este sendero, Bolívar Echeverría presenta en el breve texto titulado $E l$ ocaso del inca (2011) un análisis sobre Titu Cusi Yupanqui (1526-1571), un Inca de Vilcabamba ${ }^{7}$. Bolívar Echeverría presenta en Titu Cusi la inexorable decadencia de un proyecto civilizatorio. El "ocaso del inca" intenta reconocer los modos de adecuación y de reconstitución histórica y política a través de la escritura en su célebre Instrucción (1570). En este texto Bolívar Echeverría argumenta que la conquista es un proceso histórico-cultural aun en construcción, se entiende también que aquel proyecto civilizatorio precolombino (en este caso incaico) cae en decadencia, particularmente por su carácter utópico frente a la imposición civilizatoria europeo-moderna. Es posible sostener que el ejercicio sobre Titu Cusi

\footnotetext{
${ }^{7}$ Sobre Titu Cusi Yupanqui y su célebre Instrucción al Licenciado Lope García de Castro (1570) rescatamos, junto con la lectura de Echeverría, dos puntos de vista igualmente fundamentales. El primero es su escritura como un ejercicio de resistencia político-cultural frente al orden colonial hispano. El segundo refiere a la convergencia e interacción de modelos y tecnologías de comunicación europeas y andinas en la composición de su texto como traducción cultural y como discurso histórico (Cattan, 2011).
} 
es extensible a Tezozómoc y se resume en el reconocimiento de las estrategias de enunciación y construcción discursiva e identitaria de un tipo de subjetividad moderna nombrada como indio, que reclama, demanda y reconstruye su lugar (un no-lugar) en la modernidad occidental.

En conclusión, hemos intentado describir una aproximación filosóficopolítica donde relevamos el modo de enunciación y afirmación de un discurso sobre lo indio rastreable en la narración histórico-literaria de Tezozómoc. Lo que tenemos es una reflexión filosófico-política por lo menos específica, que se articula en la legitimación y recomposición de una historicidad rememorada a través de una "escritura codigofágica" a través de una "crónica mestiza", que "se pone en escena" devorando y recreando su sentido histórico y su lugar alternativo en la modernidad occidental. El caso de Tezozómoc es decidor en cuanto que en su escritura nos revela también una propuesta de alcance civilizatorio. En Tezozómoc y su proyecto civilizatorio vemos una filosofía política que redime la experiencia histórica del indio como agente en movimiento, como narrador literario, de un cauce identitario que lo involucra directamente y a través del cual justifica su propia existencia e historicidad. Vemos en Tezozómoc el compromiso de un pensamiento filosófico-político indio (y americano) que vectoriza diversos horizontes de pregunta (identitarios y culturales) en el entramado de su texto, que produce un constante gesto rearticulador, propositivo en un escenario adverso e impositivo de cambios culturales importantes, redireccionando un proyecto civilizatorio moderno alternativo y bifurcado en México colonial.

\section{REFERENCIAS}

Adorno, Rolena. "El indio ladino en el Perú colonial". De palabra y obra en el Nuevo Mundo. Imágenes interétnicas. En Manuel Gutiérrez Estévez, et al. (Eds.). México: Siglo Veintiuno, (1992): 369-395.

Alvarado Tezozómoc, Hernando. [1598]. Crónica Mexicana. Madrid: Dastin, 2010.

Alvarado Tezozómoc, Hernando. [1609]. Crónica Mexicáyotl. México: Imprenta Universitaria, 1949.

Añón, Valeria. La palabra despierta. Tramas de la identidad y usos del pasado en crónicas de la conquista de México. Buenos Aires: Corregidor, 2012.

Aristóteles. La Política. Madrid: Gredos, 1988. 
Bernand, Carmen. "Mestizos, mulatos y ladinos en Hispanoamérica: un enfoque antropológico de un proceso histórico", Motivos de la antropología americanista. Indagaciones en la diferencia. En Miguel León Portilla (Coord.). México: Fondo de Cultura Económica, (2001): 105-131.

Bonfil Batalla, Guillermo. "El concepto de indio en América: una categoría de la situación colonial”, Anales de Antropología 9 (1972): 105-124.

Cattan, Marguerite. "En los Umbrales de la Instrucción de Titu Cusi Yupanqui", Revista Histórica 35 (2011): 7-44.

Cornejo Polar, Antonio. Escribir en el aire. Ensayo sobre la heterogeneidad sociocultural en las literaturas andinas. Lima: Latinoamericana Editores, 2011.

Echeverría, Bolívar. Las ilusiones de la modernidad. Quito: Tramasocial, 2001.

Echeverría, Bolívar. La modernidad de lo barroco. México: Era, 2005.

Echeverría, Bolívar. Modernidad y blanquitud. México: Era, 2010.

Echeverría, Bolívar. "El ocaso del Inca”. Antología Bolivar Echeverría. Crítica de la modernidad capitalista. En Gonzalo Gonsalvez (Ed.). La Paz: Vicepresidencia del Estado Plurinacional de Bolivia-OXFAM, (2011): 203-208.

Ette, Ottmar. Literatura en movimiento. Espacio y dinámica de una escritura transgresora de fronteras entre Europa y América. Madrid: Consejo Superior de Investigaciones Científicas, 2008.

Ette, Ottmar. Viellogische Philologie. Die Literaturen der Welt und das Beispiel einer Transarealen Peruanischen Literatur. Berlin: Kadmos, 2013.

Ferrater Mora, José. Diccionario de filosofía. Barcelona: Ariel, 1994.

Garibay, Ángel María. Historia de la literatura nábuatl. El trauma de la conquista (1521-1750). México: Porrúa, 1954.

Gruzinski, Serge. "Ensayo introductorio". Passeurs, mediadores culturales y agentes de la primera globalización en el mundo ibérico, siglos XVI-XIX. En Scarlet O'Phelan y Carmen Salazar (Eds.). Lima: Instituto Francés de Estudios Andinos, (2005): 13-30. 
Gruzinski, Serge. La colonización de lo imaginario. Sociedades indígenas y occidentalización en el México español. Siglo XVI-XVIII. México: Fondo de Cultura Económica, 2004.

Heidegger, Martin. Ser y Tiempo. Buenos Aires: Fondo de Cultura Económica, 2003.

Husserl, Edmund. Erfahrung und Urteil. Praga: Academia, 2005.

Kuhn, Heinz. "The Phenomenological Concept of Horizon”. Philosophical Essays in Memory of Edmund Husserl. In Marvin Faber (Ed.). Cambridge: Harvard University Press, (1940): 106-123.

Lienhard, Martin. "La crónica mestiza en México y el Perú hasta 1620: apuntes para su estudio histórico-literario", Revista de Crítica Literaria Latinoamericana 17 (1983): 105-115.

León-Portilla, Miguel. El reverso de la conquista. Relaciones aztecas, mayas e incas. México: Editorial Joaquín Mortiz, 1964.

Lockhart, James. Los nahuas después de la Conquista. Historia social y cultural de los indios del México central, del siglo XVI al XVIII. México: Fondo de Cultura Económica, 2013.

López-Austin, Alfredo. Hombre-Dios. Religión y politica en el mundo náhuatl. México: Universidad Nacional Autónoma de México, 2014.

Navarrete, Federico. Los orígenes de los pueblos indígenas del valle de México. Los altépetly sus historias. México: Universidad Nacional Autónoma de México, 2015.

Ortega Esquivel, Aureliano. “¿Qué pregunta la filosofía desde América?”. Filosofía desde América. Temas, balances y perspectivas. En Ana Cristina Ramírez Barreto (Coord.). Quito: Abya Yala, (2011): 17-43.

O’Gorman, Edmundo. La invención de América. México: Fondo de Cultura Económica, 2001.

Pagden, Anthony. La caída del hombre natural. El indio americano y los orígenes de la etnología comparativa. Madrid: Alianza, 1988. 
Payàs, Gertrudis. El revés del tapiz. Traducción y discurso de identidad en la Nueva España (1521-1821). Madrid/Frankfurt: Iberoamericana/Vervuert, 2010.

Pratt, Mary Louise. "Arts of the Contact Zone", Profession 91 (1991): 33-40.

Romero Galván, Rubén. "Memoria, oralidad e historia en dos cronistas nahua", Estudios de cultural nábuatl 38 (2007): 165-182.

Romero Galván, Rubén. Los privilegios perdidos. Hernando Alvarado Tezozómoc y su tiempo, su nobleza y su Crónica Mexicana. México: Universidad Nacional Autónoma de México, 2003.

Romero Galván, Rubén (coord.). Historiografía mexicana. Historiografía novohispana de tradición indigena. México: Universidad Nacional Autónoma de México, 2011.

Rozat, Guy. Indios imaginarios e indios reales en los relatos de la conquista de México. México: Tava, 1993.

Yupanqui, Titu Cusi. [1570]. Instrucción del Inca Don Diego Titu Cusi Yupanqui para el muy Ilustre señor el Licenciado Lope García de Castro. Lima: Pontificia Universidad Católica del Perú, 1992.

Zavala, Silvio. La filosofía politica en la Conquista de América. Santiago de Chile: Fondo de Cultura Económica, 1994. 